\section{The effect of seven-week preparation period on body composition, strength, flexibility and aerobic endurance characteristics of a women volleyball team}

\section{7 haftalık hazırlık periyodunun bir kadin voleybol takımının vücut kompozisyonu, kuvvet, esneklik ve aerobik dayanıklılık özelliklerine etkisi}

\author{
Ender Eyuboğlu ${ }^{1}$ \\ Oğuzhan Dalkıran ${ }^{2}$ \\ Cem Sinan Aslan ${ }^{3}$
}

\begin{abstract}
The aim of this study was to determine the effect of seven-week preparation period on body composition, strength, flexibility and aerobic endurance characteristics of female volleyball players of a team in Turkish $1^{\text {st }}$ Division Volleyball League.

Healthy 9 female volleyball players (average age

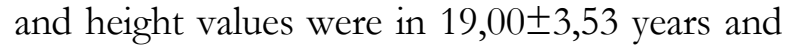
$176,13 \pm 4,30 \mathrm{~cm})$ participated voluntarily in this study. Participants' age, body weight, height, body fat percentage was determined and vertical (squad and active) jump, flexibility and aerobic endurance characteristics were measured. In order to compare differences between pre-test and post-test results Paired Sample t-Test in SPSS (Ver.14) program was used. $\alpha$ set as 0,05 .

According to the results of the comparison of the data obtained from the pre-test and post-test measurements of the participants, there were no significant differences between two tests on body mass, body fat percentage, counter movement jump, squat jump and anaerobic power, otherwise there were significant differences between tests on flexibility ( $t=-$
\end{abstract}

Özet

Bu çalışmada amaç; 7 haftalık hazırlık dönemi boyunca yapilan antrenmanların, Türkiye Voleybol Kadinlar 1. Ligi'nde yer alan bir takımın oyuncularının vücut kompozisyonu, kuvvet, esneklik ve aerobik dayanıklılık $\left(\mathrm{VO}_{2 \max }\right)$ özelliklerine etkisini belirlemektir.

Çalışmaya, herhangi bir sağlık problemi veya spor yaralanması bulunmayan, 19,00 $\pm 3,53$ yaş ve $176,13 \pm 4,30 \mathrm{~cm}$ boy ortalamasina sahip 9 kadın voleybolcu gönüllü olarak katılmıştır. Oyuncuların fiziksel özelliklerinden yaş, vücut ağırlı̆̆1, boy ve vücut yağ yüzdesi tespit edilmiş, ayrıca motorik özelliklerinden aktif ve skuat sıçrama, esneklik ve aerobik dayanıklılık kapasiteleri ön-test ve son-test olarak birer kez ölçülmüştür. Verilerin karşılaştırılmasında SPSS (Ver. 14) paket programinda yer alan Paired Sample T-test kullanılmıştır. $\alpha$ değeri 0,05 olarak kabul edilmiștir.

Katılımciların ön-test ve son-test ölçümlerinden elde edilen verilerin karşılaştırma sonuçlarına göre; 7 hafta boyunca düzenli uygulanan antrenmanlar sonucunda vücut ağırlığı, vücut yağ yüzdesi, aktif sıçrama, skuat

\footnotetext{
1 Yrd. Doç. Dr., Bartın Üniversitesi, Beden Eğitimi ve Spor Yüksekokulu, Spor Yöneticiliği, endereyuboglu@hotmail.com

2 Yrd. Doç. Dr., Mehmet Akif Ersoy Üniversitesi, Beden Eğitimi ve Spor Yüksekokulu, Antrenörlük Eğitimi, odalkiran77@hotmail.com

3 Yrd. Doç. Dr., Mehmet Akif Ersoy Üniversitesi, Beden Eğitimi ve Spor Yüksekokulu, Antrenörlük Eğitimi, sinancm@hotmail.com
} 
Eyuboğlu, E., Dalkıran, O., \& Aslan, C. S. (2016). 7 haftalık hazırlık periyodunun bir kadın voleybol takımının vücut kompozisyonu, kuvvet, esneklik ve aerobik dayanıkl11k özelliklerine etkisi. Journal of Human Sciences, 13(3), 60716079. doi: $10.14687 /$ ihs.v13i3.4249

2,811; $\mathrm{p}=0,023)$ and $\mathrm{VO}_{2 \max }(\mathrm{t}=-8,066 ; \mathrm{p}=0,000)$. siçrama ve anaerobik güç özelliklerinde anlamlı bir değişim olmazken, esneklik ( $\mathrm{t}=-2,811$; Keywords: Volleyball; body composition; $\mathrm{p}=0,023)$ ve $\mathrm{VO}_{2 \max } \quad$ ( $\mathrm{t}=-7,948$; strength; aerobic capacity; flexibility.

(Extended English abstract is at the end of this document) $\mathrm{p}=0,000)$ özelliklerinde anlamlı değişimler meydana gelmiştir.

Anahtar Kelimeler: Voleybol; vücut kompozisyonu; kuvvet; aerobik kapasite; esneklik.

\section{Giriş}

Voleybol sporu; kısa süreli egzersiz periyotları ve dinlenmeyle değişmeli olarak yapılan bir interval sporu olarak tanımlanabilir (Turnagöl, 1994). Oyun süresi, çabuk ve doğru oynama gerekliliği göz önüne alındığında, kuvvet, sürat, dayanıklılık, hareketlilik, beceri ve koordinasyon gibi temel motorik özelliklerin tümünün olması gerekliliği ortaya çıkar. Ancak bütün takım sporlarında olduğu gibi, topa sahip olmak için yapılan mücadelede çabuk kuvvet ve kuvvette devamlılık gibi koordinatif yeteneklerin de ön plana çıtı̆̆ı görülmektedir (Koç ve ark., 2007).

Bu spor dalının gerektirdiği fiziksel ve fizyolojik yapı, başarılı olmada önemli bir yer tutmaktadır (Lale ve ark., 2003). Mükemmel bir tekniğe ve taktiğe sahip olan bir voleybolcunun ancak temel motorik özelliklerinin çok iyi tatbiki sonucu başarı elde edilebilir (İpek ve Ziyagil, 2002; Koç, 1996). Bunun yanında sporcuların fiziksel özellikleri, zihinsel özellikleri, teknik-taktik ve deneyim gibi parametreleri de başarının elde edilmesinde önemli kriterlerden biridir (Koyomo ve Kazion, 1994; Gökdemir ve Koç, 2000).

Voleybol sporu, gelişmiş fiziksel uygunluk ve antropometrik özellik gereksinimi gösteren spor dallarındandır (Göral ve ark., 2009). Fiziksel uygunluk bağlamında, voleybol oyuncusunun antropometrik özellikleri ve sıçrama yeteneği, performans açısından takımın başarısında önemli etkendir (Clarke, 1975). Fiziksel uygunluğu yeterli olmayan sporcularda erken ortaya çıkan yorgunluk, performansın en üst düzeye ulaşmasında önemli etkisi olan sinir-kas koordinasyonunu bozar ve teknik kapasitenin arzulanan seviyede uygulanmasını güçleştirir (Temoçin ve ark., 2004; Herzog, 1996). Bu hareketlerin uygulanmasında kuvvetin, esnekliğin, anaerobik-aerobik gücün ve çabukluğun önemi büyüktür (Kartal ve Günay, 1995; Csanadi, 1973). Sezon öncesi ve sezon içinde uygulanan antrenman programı sporcuların istendik fiziksel uygunluk seviyesine gelebilmeleri için çok önemlidir. Bu nedenle, sporcuların fiziksel ve fizyolojik kapasitelerinin tespiti ve bu tespitlerin antrenman programına yön vermesi voleybolda başarının elde edilmesinin koşullarından biridir.

\section{Amaç}

Bu çalışmada amaç; 7 haftalık hazırlık dönemi boyunca gerçekleştirilen çalışmaların, Türkiye Voleybol Kadınlar 1. Ligi'nde yer alan bir takımın 9 oyuncusunun vücut kompozisyonu, kuvvet, esneklik ve aerobik dayanıkl1lı özelliklerine etkisini belirlemektir.

\section{Yöntem}

Ön-test ve son-test şeklinde dizayn edilen bu çalışmanın gerçekleştirilmesinde deneysel yöntem kullanılmıştır.

\subsection{Denekler}

Çalışmaya, Türkiye Voleybol Kadınlar 1. Ligi’nde yer alan bir takımın 9 kadın voleybol

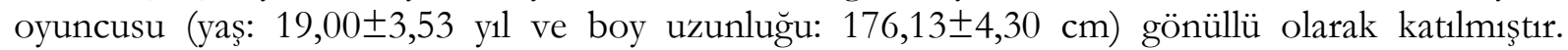
Oyunculardan sağlık problemi olanlar, spor yaralanması yaşayanlar ya da ölçümler esnasında yeni 
Eyuboğlu, E., Dalkıran, O., \& Aslan, C. S. (2016). 7 haftalık hazırlık periyodunun bir kadın voleybol takımının vücut kompozisyonu, kuvvet, esneklik ve aerobik dayanıkl11k özelliklerine etkisi. Journal of Human Sciences, 13(3), 60716079. doi: $10.14687 /$ ihs.v13i3.4249

iyileşmiş olan sporcular çalışmaya dâhil edilmemiştir. Ölçümler hazırlık döneminin başında ve lig başlamadan bir hafta önce takımın sürekli antrenman yaptığı spor salonunda gerçekleştirilmiştir.

\subsection{Prosedür}

Yedi hafta boyunca; Pazartesi-Salı-Perşembe-Cuma günleri çift antrenman, ÇarşambaCumartesi günleri ise tek antrenman yapılmıştır. Pazar günleri dinlenmeye ayrılmıştır.

Sabah antrenmanları: Teknik-taktik antrenmanlar yapılmıştır.

Pazartesi-Cuma akşam antrenmanları: Aerobik ve anaerobik dayanıklılık antrenmanları yapılmıştır. Sal1-Perșembe-Cumartesi: Ek ağırlık ile kuvvet çalıșmaları; ilk 4 hafta sub-maksimal, sonraki 2 hafta maksimal, son hafta ise çabuk kuvvet antrenmanları olarak gerçekleştirilmiştir.

Esneklik antrenmanları, her birim antrenmanda gerçekleştirilen ısınma ve soğuma bölümlerinde yer alan hareketler haricinde özel olarak çalışılmamıştır.

ACSM (2000), fiziksel uygunluk testleri belirli bir süre içinde uygulanması gerektiğinde, olumsuz etkilerin ortadan kalkması için ölçümlerin "dinlenme kan basıncı ve kalp atım sayısı beden kompozisyonu - kalp solunum sistemi dayanıkl1lı̆ı - kassal uygunluk - esneklik" siralamas1 ile yapılmasını önermektedir. Çalışmada, bu öneriye benzer bir yol izlenerek katılımcıların bedensel özellikleri ile ilgili ölçümler yapıldıktan sonra sırasıyla; bacak kuvveti, dikey sıçrama, otur-eriş esneklik testi ve 20 m Mekik koşusu testleri uygulanmıştır.

Fiziksel aktivitelerin istenilen etkinlikte uygulanabilmesi için, en uygun vücut 1sısı 38,5-39 santigrat dereceler arasındadır ve sadece 10 dakikalık düz koşu bile vücudu belirtilen 1s1 derecelerine ulaştırmaktadır (Özer, 2006). Bu nedenle, testler uygulanmadan önce katılımcılara 15 dakikalık ısınma süresi tanınmıştır. Tüm katılımcılar aynı prosedürle isınmıştır. Düşük tempolu koşu, kalistenik hareketler ve sporcuların kuvvet özelliklerinin minimum düzeyde etkilenmesi adına, her bir tekrarı 5-6 saniyeden daha fazla sürmeyen açma-germe egzersizleri ile 1sınma süreci tamamlanmıştır. Testlerin uygulanmasından önce; testlerin ne şekilde uygulanacağı, vücudun alması gereken pozisyon, her bir uygulamanın ne kadar sürmesi gerektiği vb. bilgiler katılımcılara gösterilerek açıklanmıştır. Katılımcılara, aerobik dayanıklılık testi haricindeki her bir test, $5 \mathrm{dk}$ dinlenme aralığı ile iki defa uygulanmıș ve daha iyi olan sonuç kaydedilmiștir.

\section{3. Ölçüm Yöntemleri}

Fiziksel ölçümlerden vücut ağırlığ1 ve vücut yağ yüzdesi Tanita (Japonya) marka ve 100 gram (gr) hassaslığındaki vücut yağ analizörüyle, boy ölçümü ise "Holtaine" (İngiltere) marka stadiometre ile $0,1 \mathrm{~cm}$ duyarll1ıkta yapılmıştır. Vücut kompozisyonu ile ilgili ölçümler sabah saatlerinde, sporcular herhangi bir gıda maddesi almadan gerçekleştirilmiştir.

Performans testlerinden dikey siçrama ve anaerobik güç Newtest 300 (Finlandiya) test bataryasında yer alan aktif ve skuat sıçrama testleriyle belirlenmiştir. Aktif sıçramada sporcular zemin üzerindeyken eller belde ayaktan dizler üzerinde çökerek sıçramaları istenmiştir, skuat sıçramada ise sporcular yine eller belde olacak şekilde zemin üzerinde $90^{\circ}$ sabit skuat pozisyonundayken sıçramaları istenmiş ve elde edilen sonuçlar yükseklik (cm) ve güç (W) birimleri kullanılarak kaydedilmiştir.

Esnekliği ölçmek için “Otur-Eriş Esneklik Testi” kullanılmıştır, Zorba (1999), testin güvenilirliğini 0,83 olarak aktarmıştır.

Maksimal $\mathrm{VO}_{2}$ 'nin hesaplanmasında "20 m Mekik Koşusu Testi” tercih edilmiştir. Test, $\mathrm{VO}_{2 \max }$ hesaplamada saha testleri arasında yaygın şekilde kullanılan ve en yüksek geçerlik ve güvenirliğe sahip testlerden biridir (Ramsbottom ve ark, 1988). Testten elde edilen sonuçların $\mathrm{VO}_{2 \max }$ 'adönüştürülmesi, Ramsbottom ve ark. (1988)'ın geliştirdiği hesaplama yöntemi ile yapılmıştır.

\subsection{Verilerin Analizi}

Katılımcıların ölçümlerinden elde edilen verilerin minimum-maksimum ve ortalama değerlerinin belirlenmesi için SPSS (Ver. 14) paket programında yer alan "Descriptive Statistic" analiz yöntemleri, verilerin karşılaştırılmasında ise "Shapiro-Wilk" testi ile verilerin normal dağglım 
Eyuboğlu, E., Dalkıran, O., \& Aslan, C. S. (2016). 7 haftalık hazırlık periyodunun bir kadın voleybol takımının vücut kompozisyonu, kuvvet, esneklik ve aerobik dayanıkll11k özelliklerine etkisi. Journal of Human Sciences, 13(3), 60716079. doi: $10.14687 /$ ihs.v13i3.4249

gösterdiği belirlendiğinden "Paired Sample t-Test" kullanılmıştır. $\alpha$ değeri 0,05 olarak kabul edilmiştir.

\section{Bulgular}

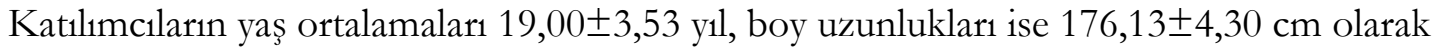
belirlenmiştir. Katılımcılara uygulanan ölçümlerden elde edilen diğer verilerin ortalama değerleri ve karşılaştırma sonuçları tablo halinde gösterilmiştir.

Tablo 1. Katılımcıların ön-test ve son-test değerleri ve karşılaştırma sonuçları (Paired Sample t-Test)

\begin{tabular}{|c|c|c|c|c|}
\hline Ölçümler & Test I & Test II & $t$ & $p$ \\
\hline $\begin{array}{l}\text { Vücut Ağırlı̆̆1 } \\
\text { (kg) }\end{array}$ & $60,46 \pm 4,74$ & $59,11 \pm 3,86$ & 0,666 & 0,524 \\
\hline $\begin{array}{l}\text { Yağ Yüzdesi } \\
(\%)\end{array}$ & $18,73 \pm 2,85$ & $18,90 \pm 2,92$ & $-0,395$ & 0,703 \\
\hline $\begin{array}{l}\text { Skuat Siçrama } \\
(\mathrm{cm})\end{array}$ & $29,00 \pm 3,24$ & $29,56 \pm 4,33$ & $-0,398$ & 0,701 \\
\hline $\begin{array}{l}\text { Aktif Siçrama } \\
(\mathrm{cm})\end{array}$ & $35,67 \pm 4,30$ & $34,56 \pm 3,13$ & 1,104 & 0,302 \\
\hline $\begin{array}{l}\text { Anaerobik Güç } \\
\text { (W) }\end{array}$ & $2446,10 \pm 468,08$ & $2366,30 \pm 351,60$ & 0,654 & 0,531 \\
\hline $\begin{array}{l}\text { Esneklik } \\
(\mathrm{cm})\end{array}$ & $29,39 \pm 7,73$ & $31,47 \pm 6,52$ & $-2,811$ & $0,023^{*}$ \\
\hline $\begin{array}{l}\text { Mekik Koşusu } \\
\text { (adet) }\end{array}$ & $58,89 \pm 9,31$ & $77,22 \pm 9,12$ & $-8,066$ & $0,000^{*}$ \\
\hline $\begin{array}{l}\mathrm{VO}_{2 \max } \\
(\mathrm{ml} / \mathrm{kg} / \mathrm{dk})\end{array}$ & $39,12 \pm 3,09$ & $45,01 \pm 2,79$ & $-7,948$ & $0,000 *$ \\
\hline
\end{tabular}

Katılımcıların ön-test ve son-test ölçümlerinden elde edilen verilerin karşılaştırma sonuçlarına göre; 7 hafta boyunca düzenli uygulanan antrenmanlar sonucunda vücut ağırllğı, vücut yağ yüzdesi, aktif sıçrama, skuat sıçrama ve anaerobik güç özelliklerinde anlamlı bir değişim olmazken, esneklik ve $\mathrm{VO}_{2 \max }$ özelliklerinde anlamlı değişimler meydana gelmiştir.

\section{Tartışma}

Güncel literatürde, Türkiye'deki liglerde yer alan kadın voleybolcuların fiziksel ve motorik özellikleri üzerine sınırlı sayıda araştırma bulunmaktadır ve var olan çalışmaların birçoğu da uzun yıllar önce yapılmıştır. Bu nedenle konu tartışılırken, sınırlı sayıda çalışma sonuçları ile desteklenebilmiştir.

Bu çalışma sonucunda katılımcıların yaş ortalamaları 19,00 yıl, vücut ağırlıkları; çalışmanın başlangicında $60,46 \mathrm{~kg}$ ve boy uzunluklar1 $176,13 \pm 4,30 \mathrm{~cm}$, vücut yağ oranları ise $\% 18,73 \pm 2,85$ olarak tespit edilmiştir. Literatür incelendiğinde,; Atan ve ark. (2012) çalışmalarında, kadın voleybolcuların yaşlarını 21,15 yıl, vücut ağırlıklarını $62,25 \mathrm{~kg}$ ve boylarını $174,05 \mathrm{~cm}$, Koç ve Aslan (2010) sirasiyla; 20,10 y1l, 65,80 kg ve $177,50 \mathrm{~cm}$, Önder ve Eler (2008) sirasiyla; 24,21 y1l, $68,00 \mathrm{~kg}$ ve $182,05 \mathrm{~cm}$, Baktaal (2008) sirasiyla; $19,20 \mathrm{yll}, 67,80 \mathrm{~kg}$ ve 175,00 cm, Koç ve ark. (2007) ise sirasıyla; 22,40 yıl, 59,10 kg ve $170,30 \mathrm{~cm}$ olarak belirlemişlerdir. Kadın voleybolcuların vücut yağ yüzdesini Ön ve ark. (2014) \%12,87, Atan ve ark. (2012) \%12,55, Cink1llı (2011) \%16,3 ve $\% 11,9$, Çavlica ve ark. (2009) \%22,8 ve \%23,4, Önder ve Eler (2008) ise \%21,93 olarak belirlemiştir. 
Eyuboğlu, E., Dalkıran, O., \& Aslan, C. S. (2016). 7 haftalık hazırlık periyodunun bir kadın voleybol takımının vücut kompozisyonu, kuvvet, esneklik ve aerobik dayanıkl11k özelliklerine etkisi. Journal of Human Sciences, 13(3), 60716079. doi: $10.14687 /$ ihs.v13i3.4249

Literatürde kadın voleybolcuların motorik özelliklerini belirlemiș çalıșmalar incelendiğinde; Atan ve ark. (2012) dikey sıçrama ortalamasını 28,99 cm, anaerobik güç ortalamasinı $2431,8 \mathrm{~W}$, esneklik ortalamasin $16,55 \mathrm{~cm}$ ve $\mathrm{VO}_{2 \text { maks }}$ ortalamasinı ise 32,45 $\mathrm{ml} / \mathrm{kg} / \mathrm{dk}$ olarak tespit etmiştir. Çon ve ark. (2012) aktif sıçramayı 26,9 cm, statik sıçramayı 24,8 cm, esnekliği 17,6 cm, Baktaal (2008) dikey sıçramayı 27,66 cm ve 29,25 cm olarak bulmuşlardır. Önder ve Eler (2008) esneklik değerini 30,52 cm, Koç ve ark. (2007) 18,30 cm, Şifaver (1991) ise antrenmanlar öncesinde $32,30 \mathrm{~cm}$, sonrasinda ise $34,80 \mathrm{~cm}$ olarak bulmuşlardır. Gökdemir ve Koç (2000) çalışmalarında kadın voleybolcuların $\mathrm{VO}_{2 \text { maks }}$ değerlerini $35,30 \mathrm{ml} / \mathrm{kg} / \mathrm{dk}$, esneklik değerlerini ise $25,58 \mathrm{~cm}$ olarak tespit etmişlerdir.

Literatürde yer alan, Türkiye liglerinde voleybol oynayan kadın sporcularla yapılmış fiziksel ve motorik özellikleri belirleyen çalışma sonuçları ile bu çalışmada elde edilen sonuçlar genelde benzemektedir. Bu durumda, evreni oluşturan diğer örneklemler ile bu çalışmada yer alan katılımcılar benzer özelliklere sahiptir denilebilir.

Kadın voleybolculardan elde edilen birinci ve ikinci ölçüm sonuçları karşılaştırıldığında, 7 haftalık antrenmanlar sonucunda fiziksel özelliklerden vücut ağırllğ̣ ve vücut yă̆ yüzdesinde herhangi bir anlamlı değişim oluşmadığ görülmüsstür. Yine, motorik özelliklerden aktif ve skuat sıçrama ile anaerobik güç özelliklerinde de anlamlı bir değişim gözlenmezken, $\mathrm{VO}_{2 \text { maks }}$ ve esneklik özelliklerinde istatistiksel olarak anlamlı artıslar tespit edilmiştir.

Literatür incelendiğinde, kadın voleybolcuların hazırlık sezonu öncesi ve sonrası fiziksel ve motorik özelliklerini karşılaştıran bir çalışmaya rastlanmamıştır. Bu tarz çalışmalar genelde erkek sporcular ile yoğunlukla da futbol branşında gerçekleştirilmiştir. Bu çalışmalardan elde edilen sonuçlar ise farklılık göstermektedir. Örneğin; Erkmen ve ark. (2005) profesyonel futbolcularla gerçekleştirdikleri çalışmalarında hazırlık dönemi sonunda vücut yağ oranı ve $\mathrm{VO}_{2 \text { maks }}$ özelliklerinde anlamlı değişim belirlerken anaerobik güç özelliğinde bir fark bulamamışlardır. Aslan ve Karakollukçu (2010) vücut ağırlığı, bacak kuvveti ve anaerobik güçte bir değişiklik tespit edemezken, vücut yă̆ oranı, dikey sıçrama ve esneklik özelliklerinde anlamlı değişiklikler olduğunu bildirmişlerdir. Açıkada ve ark. (1996) ise; vücut ağırlı̆̆1 ve yağ yüzdesinde anlamlı bir azalma olduğunu fakat aktif ve skuat sıçramada anlamlı bir değişimin olmadığını belirlemişlerdir. Yıldırım (2013) kadın futbolcularla gerçekleştirdiği çalışmasında, 8 haftalık bir antrenman süreci sonunda vücut kompozisyonu, dikey sıçrama, bacak kuvveti ve esneklik özelliklerinde anlamlı bir değişim tespit edememiştir. Özveren ve ark. (2016) kadın voleybolcularla gerçekleştirdiği çalışmalarında, klasik voleybol antrenmanı yapan grupta sadece esneklik ve $\mathrm{VO}_{2 \text { maks }}$ özelliklerinde artış olduğunu, ekstradan pliometrik antrenman yapan grupta ise ayrıca sürat, sıçrama ve diğer kuvvet parametrelerinde de anlamlı artış olduğunu, Baktaal (2008) ise kadın voleybolcularda 6 haftalık pliometrik içerikli kuvvet antrenmanları sonucunda, dikey sıçramada anlamlı bir farkın olmadığını bildirmiştir.

\section{Sonuç}

Sonuç olarak; bu çalışmada elde edilen veriler ışı̆̆ında; kadın voleybolcularda 7 haftalık hazırlık süresinin $\mathrm{VO}_{2 \text { maks }}$ ve esneklik özelliklerini geliştirmeye yeterken, özellikle kuvvet ve güç artışı için sürenin yetmediği ya da 7 hafta boyunca yapılan antrenmanların bahsi geçen özellikleri geliştirmede yeterli olmadığı söylenebilir. Voleybol sporunun müsabaka yapısı gereği, performansin sergilenmesinde anaerobik özelliklerin daha çok ön plana çıtı̆̆1 düşünülürse uygulanan antrenman programlarının bu özellikleri geliştirmede daha etkin olması gerekliliği ortaya çıkmaktadır. 
Eyuboğlu, E., Dalkıran, O., \& Aslan, C. S. (2016). 7 haftalık hazırlık periyodunun bir kadın voleybol takımının vücut kompozisyonu, kuvvet, esneklik ve aerobik dayanıkl11k özelliklerine etkisi. Journal of Human Sciences, 13(3), 60716079. doi: $10.14687 /$ ihs.v13i3.4249

\section{Kaynaklar}

ACSM-Amerikan Collage of Sports Medicine., (2000). Guidelines For Exercise and Prescription. $5^{\text {th }}$ Edition. Williams \& Wilkins, Baltimore.

Açıkada, C., Özkara, A., Hazır, T., Aşçı, A., Turnagöl, H., Tinazcı, C., Ergen, E., (1996). Bir futbol takımında sezon öncesi hazırlık antrenmanlarının bir kısım kuvvet ve dayanıklılık özellikleri üzerine etkisi. Spor Bilimleri Dergisi.7(1), 24-32.

Aslan, C. S., Karakollukçu, M., (2010). Sezon öncesi hazırlık çalısmalarının bir süper ligtakımının seçilmiş fiziksel ve fizyolojik özelliklerine etkileri. Spormetre Beden Ë̈itimi ve Spor Bilimleri Dergisi. 7(2), 51-56.

Atan, T., Ayyıldız, T., Akyol Ayyıldız, P., (2012). Farklı branşlarla uğraşan bayan sporcuların bazı fiziksel uygunluk değerlerinin incelenmesi. Selcuk Üniversitesi Beden Ë̆gitimi ve Spor Bilim Dergisi. 14(2), 277-282.

Baktaal, D. G., (2008). 16-22 yaş bayan voleybolcularda pliometrik çalışmaların dikey sıçrama üzerine etkilerinin belirlenmesi. Çukurova Üniversitesi Sağlık Bilimleri Enstitüsü Yüksek Lisans Tezi.

Cinkı1lı, E., (2011). Voleybolcularda somatotip ve vücut bileşiminin belirlenmesi. Ankara Üniversitesi Sosyal Bilimler Enstitüsü Yüksek Lisans Tezi.

Clarke, O. H., (1975). Exercise Physiology. Prentice Hall, New Jersey, USA. (Alıntı: Duyul Albay, M., Tutkun, E., Ağaoğlu, Y.S., Canikli, A., Albay, F., (2008). Hentbol, voleybol ve futbol üniversite takımlarının bazı motorik ve antropometrik özelliklerinin incelenmesi. Spormetre Beden Eğitimi ve Spor Bilimleri Dergisi. 6(1), 13-20.)

Csanadi, A., (1973). Futbol Antrenmanı. (çev: Yağızaltı, T.), TFF Yayını, Ankara. (Alıntı: Duyul Albay, M., Tutkun, E., Ağaoğlu, Y.S., Canikli, A., Albay, F., (2008). Hentbol, voleybol ve futbol üniversite takimlarinin bazi motorik ve antropometrik özelliklerinin incelenmesi. Spormetre Beden Eg̈itimi ve Spor Bilimleri Dergisi. 6(1), 13-20.)

Çavlıca, B., Bereket Yücel, S., Darçin, N., Mirzai, İ. T., Erbüyün, K., (2009). Profesyonel kadın voleybolcularda ağr1 duyumunun menstrual döngü ile ilişkisi. A ğr. 21(1), 29-35.

Çon, M., Akyol, P., Tural, E., Taşmektepligil, M.Y., (2012). Voleybolcuların esneklik ve vücut yă̆ yüzdesi değerlerinin dikey sıçrama performansına etkisi. Selçuk Üniversitesi Beden Eğitimi ve Spor Bilim Dergisi, 14(2). 202-207.

Dönmez, E., Aykora, E., (2016). Kadın voleybolcularda Tabata protokolüne göre uygulanan pliometrik egzersizlerinin kuvvet parametrelerine etkisi. $14^{\text {th }}$ International Sport Sciences Congress Proceedings Book, Antalya.

Erkmen, N., Kaplan, T., Taşkın, H., (2005). Profesyonel futbolcuların hazırlık sezonu fiziksel ve fizyolojik parametrelerinin tespiti ve karşılaştırılması. Spormetre Beden Eğitimi ve Spor Bilimleri Dergisi. 3(4), 137-144.

Gökdemir, K., Koç, H., (2000). Elit düzeydeki basketbolcu ve voleybolcu bayan sporcuların bazı fiziksel ve fizyolojik özelliklerinin mukayese edilmesi. Dumlupınar Üniversitesi Sosyal Bilimler Dergisi. 4, 297-303.

Göral, K., Saygın, Ö., Karacabey, K., Gelen, E., (2009). Tenisçiler ile voleybolcuların bazı fiziksel uygunluk özelliklerinin karşılaştırılması. New World Sciences Academy. 4(3), 227-235.

Herzog, W., (1996). Muscle function in movement and sport. The American Journal of Sport Medicine, 24(6), 14. (Alıntı: Duyul Albay, M., Tutkun, E., Ağaoğlu, Y. S., Canikli, A., Albay, F., (2008). Hentbol, voleybol ve futbol üniversite takımlarının bazı motorik ve antropometrik özelliklerinin incelenmesi. Spormetre Bed. Ë̆. ve Spor Bil. Dergisi. 6(1), 13-20.)

İpek, Z., Ziyagil, M.A., (2002). Erkek ve bayan voleybolcuların fiziksel özellikleri ve fizyolojik kapasitelerinin sedanterlerle karşılaştırılması. Beden Eğitimi ve Spor Bil. Dergi. 4(2), 12- 16.

Kartal, R., Günay M., (1995). Sezon öncesi yapılan hazırlık antrenmanının futbolcuların bazı fizyolojik parametrelerine etkisi. Futbol Bilim ve Teknolojisi Dergisi, ll(1), 24-25. 
Eyuboğlu, E., Dalkıran, O., \& Aslan, C. S. (2016). 7 haftalık hazırlık periyodunun bir kadın voleybol takımının vücut kompozisyonu, kuvvet, esneklik ve aerobik dayanıkl11k özelliklerine etkisi. Journal of Human Sciences, 13(3), 60716079. doi: $10.14687 /$ ihs.v13i3.4249

Koç, H., (1996). 14-16 yaş grubu hentbolcu ve beden eğitimi dersi alan öğrencilerin bazı fiziksel ve fizyolojik parametrelerinin eurofit test bataryasında değerlendirilmesi. Gazi Üniversitesi Sağllk Bilimler Enstitüsü Yüksek Lisans Tezi.

Koç, H., Aslan, C. S., (2010). Comparing some physical and physiological parameters of female and male sportsmen in different branches. $10^{\text {th }}$ International Scientific Conference "Perspectives in Physical Education and Sport" Book of Abstracts, Constanta, Romania.

Koç, H., Özcan, K., Pulur, A., Ayaz, A., (2007). Elit bayan hentbolcular ile voleybolcuların bazı fiziksel ve fizyolojik parametrelerinin karşlaştırılması. Spormetre Beden Eğitimi ve Spor Bilimleri Dergisi, 5(3). 123-128.

Koyomo, S., Kazion, S., (1994). Voleybolcuların fiziksel yeteneklerinin değerlendirilmesi için fiziksel testler ve standartlar. Çev.: H. Turnagöl, Voleybol Bilim ve Teknoloji Dergisi. 1, 18-23.

Lale, B., Müniroğlu, S., Çoruh, E. E., Sunay, H., (2003). Türk erkek voleybol milli takımının somatotip özelliklerinin incelenmesi. Spormetre Bed. Ĕg. ve Spor Bilimleri Dergisi. 1(1), 53-56.

Ön, S., Diker, G., Özkamçı, H., (2014). Adolesan voleybolcularda menstrual döngünün anaerobik güce ve aktif sıçrama performansına etkisi. NWSA-Sports Sciences. 9(2), 32-42.

Önder, H. U., Eler, S., (2008).Ankara ili birinci lig takımlarında oynayan bayan voleybolcuların baz1 fiziksel ve fizyolojik parametrelerinin incelenmesi. Atatürk Journal of Physical Education and Sport Sciences (ATABESBD). 10(3), 15-22.

Özer, K., (2006). Fizikesel Uygunluk. Nobel Yayınlar1, Ankara.

Özveren, Y., Emine Kutlay, E., Özçaldıran, B., Özsu, İ. (2016). Genç kadın voleybolcularda 12 haftalık plyometrik antrenmanların bazı biyomotor yetiler üzerine etkileri. $14^{\text {th }}$ International Sport Sciences Congress Proceedings Book, Antalya.

Ramsbottom, R., Brewer, J., Williams, C., (1988). A progressive shuttle run test to estimate maximal oxygen uptake. British Journal of Sports Medicine. 22, 141-144.

Şifaver, A. Ü., (1991). Sezon öncesi 8 haftalık antrenman uygulamasının Selçuk Üniversitesi bayan voleybol takımı vücut kompozisyonu ve anaerobik güce etkilerinin araştırılması. Selçuk Üniversitesi Sağlık Bilimleri Enstitüsü Yüksek Lisans Tezi.

Temoçin, S., Ek, R. O., Tekin, T. A., (2004). Futbolcularda sürat ve dayanıkl1lığın solunumsal kapasite üzerine etkisi. Spormetre Beden Ë̆itimi ve Spor Bilimleri Dergisi. 2(1), 31-35.

Turnagöl, H. H., (1994). Voleybolda enerji sistemleri. Voleybol Bilim ve Teknoloji Dergisi. 2, 34-37.

Yıldırım, H., (2013). Bayan futbolcularda 8 haftalık çabuk kuvvet antrenmanları sonrasında fiziksel ve motorik özelliklerindeki değişimin incelenmesi. 6. Spor Bilimleri Öğrenci Kongresi, Kayseri.

Zorba, E., (1999). Herkes İ̧̧in Spor ve Fiæ̧iksel Uygunluk. G,S,G,M, Eğitim Dairesi Yay., Ankara.

\section{Extended English Abstract}

\section{Introduction}

Volleyball is a sport that consists of short time performances with rest intervals (Turnagöl, 1994). When the properties of this sport, as duration of game, the need to play fast and proper, are considered, it is clear that the players must have high level of basic motor skills as strength, velocity, endurance, agility and coordination. However, as in all team sports, it is clear that players need to have explosive strengthand muscular endurance when trying to catch the ball (Koç et al, 2007).

Inadequate physical fitness of athletes causes early onset of fatigue, and this process disrupts proper functioning of neuromuscular coordination and results with unsatisfactory level of technical performance (Temoçin et al, 2004; Herzog, 1996). Strength, flexibility, aerobicanaeorobic power and quickness have important role in this process (Kartal and Günay, 1995; 
Eyuboğlu, E., Dalkıran, O., \& Aslan, C. S. (2016). 7 haftalık hazırlık periyodunun bir kadın voleybol takımının vücut kompozisyonu, kuvvet, esneklik ve aerobik dayanıkl11k özelliklerine etkisi. Journal of Human Sciences, 13(3), 60716079. doi: $10.14687 /$ ihs.v13i3.4249

Csanadi, 1973). Therefore, to determine the physical and physiological capacities of the athletes and orientation of this determination to the training program is one of the conditions for success in the volleyball.

\section{Purpose}

The aim of the study was to determine the effects of 7 week preparatory training session on body composition, strength, flexibility and aerobic endurance of female players of a volleyball team in Turkish 1. Division League.

\section{Method and material}

Experimental method was used in this study and designed as pre-test and post-test. 9 female volleyball players from a team of a Turkish 1 . Division League voluntarily participated to this study. The players who had health problems, sports injuries or already in rehabilitation process were excluded from the study. The measurements were applied twice, first in the beginning of the preparatory period and second one week before opening match of the league.

\subsection{Procedures}

For seven weeks; two training sessions a day for Monday-Tuesday-Thursday-Friday, one training session a day for Wednesday-Saturday were made, and Sunday was the rest day.

Morning sessions: technical-tactical

Monday and Friday evenings: Trained for aerobic and anaerobic endurance.

Tuesday-Thursday-Saturday: strength training with additional weights. First 4 weeks sub-maximal, next 2 weeks maximal, last week explosive strength.

Flexibility exercises have not been performed except for the movements in the warm-up and cool-down sections in each workout.

If numerous physical fitness tests have to be applied in a short time, ACSM (2000) recommends to take measurements in this order: resting blood pressure and heart rate-body composition-cardiovascular system endurance-muscular fitness-flexibility. In this study a similar way was used for measurements as, anthropometric measurements, leg strength, vertical jump, sit and reach test and $20 \mathrm{~m}$ shuttle run test. Measurements' order differed from ACSM's recommendation because of shorter time period. All of the tests' procedure had been shown to participants before performing. Measurements had been applied to participants twice with 5minute rest periods between trials, only aerobic endurance test performed once.

\subsection{Data collection}

Physical measurements were made by Tanita (Japan) body fat analyser for body fat percentage and Holtain (UK) stadiometer for height. Body composition measurements were taken in the morning and without consuming food.

Counter movement and squat jump tests used for vertical jump and anaerobic power by using Newtest 300 (Finland) and data were recorded as height (cm) and power (w). Sit and reach test was used to measure flexibility and $20 \mathrm{~m}$ Shuttle Run Test for $\mathrm{VO}_{2 \max }$. Conversion of the results obtained from the test to $\mathrm{VO}_{2 \max }$, was made by the calculation method of Ramsbottom et al. (1988).

\subsection{Evaluation of data}

In order to determine the maximum-minimum and mean data and compare differences between pre-test and post-test results "Descriptive Statistic" and "Paired Sample t-Test" in SPSS (Ver.14) program was used. $\alpha$ set as 0,05 . 
Eyuboğlu, E., Dalkıran, O., \& Aslan, C. S. (2016). 7 haftalık hazırlık periyodunun bir kadın voleybol takımının vücut kompozisyonu, kuvvet, esneklik ve aerobik dayanıkl11ı özelliklerine etkisi. Journal of Human Sciences, 13(3), 60716079. doi: $10.14687 /$ ihs.v13i3.4249

\section{Results}

Participants' mean age and height values were $19,00 \pm 3,53$ years, $176,13 \pm 4,30 \mathrm{~cm}$. the other mean values and comparison results of participants are given in Table 1.

Table 1. Pre-test and post-test mean values and correlation results of participants (Paired Sample t-Test)

\begin{tabular}{|c|c|c|c|c|}
\hline Measurements & Test I & Test II & $T$ & $p$ \\
\hline $\begin{array}{l}\text { Body Mass } \\
(\mathrm{kg})\end{array}$ & $60,46 \pm 4,74$ & $59,11 \pm 3,86$ & 0,666 & 0,524 \\
\hline $\begin{array}{l}\text { Body Fat Percentage } \\
(\%)\end{array}$ & $18,73 \pm 2,85$ & $18,90 \pm 2,92$ & $-0,395$ & 0,703 \\
\hline $\begin{array}{l}\text { Squat Jump } \\
(\mathrm{cm})\end{array}$ & $29,00 \pm 3,24$ & $29,56 \pm 4,33$ & $-0,398$ & 0,701 \\
\hline $\begin{array}{l}\text { Counter Movement Jump } \\
(\mathrm{cm})\end{array}$ & $35,67 \pm 4,30$ & $34,56 \pm 3,13$ & 1,104 & 0,302 \\
\hline $\begin{array}{l}\text { Anaerobic Power } \\
\text { (W) }\end{array}$ & $2446,10 \pm 468,08$ & $2366,30 \pm 351,60$ & 0,654 & 0,531 \\
\hline $\begin{array}{l}\text { Flexibility } \\
(\mathrm{cm})\end{array}$ & $29,39 \pm 7,73$ & $31,47 \pm 6,52$ & $-2,811$ & $0,023^{*}$ \\
\hline $\begin{array}{l}20 \text { m Shuttle Run Test } \\
\text { (number) }\end{array}$ & $58,89 \pm 9,31$ & $77,22 \pm 9,12$ & $-8,066$ & $0,000^{*}$ \\
\hline $\begin{array}{l}\mathrm{VO}_{2 \max } \\
(\mathrm{ml} / \mathrm{kg} / \mathrm{min})\end{array}$ & $39,12 \pm 3,09$ & $45,01 \pm 2,79$ & $-7,948$ & $0,000^{*}$ \\
\hline
\end{tabular}

According to the results of the comparison of the data obtained from the pre-test and post-test measurements of the participants, there were no significant differences between two tests on body mass, body fat percentage, counter movement jump, squat jump and anaerobic power, otherwise there were significant differences between tests on flexibility and $\mathrm{VO}_{2 \max }$.

\section{Discussion}

Consequently, from the data obtained in this study show that 7 weeks preparatory programme was insufficient for developing some motor skills especially as strength and power, but could improve $\mathrm{VO}_{2 \max }$ and flexibility. It can be said that the training performed over seven weeks is not enough to improve these features such as strength and power. 